\title{
Common Pacemaker Problems: Lead and Pocket Complications
}

\author{
Enes Elvin Gul and Mehmet Kayrak \\ Selcuk University, \\ Meram School of Medicine, \\ Cardiology Department Konya, \\ Turkey
}

\section{Introduction}

Pacemakers may cause undesirable complications during and after implantation. Complications associated with the implantation procedure are uncommon, but include bleeding, infection, or collapsed lung. Generally, each of these problems can be treated quite effectively. Though rare, pacemaker problems can occur long after the implantation procedure. These "late" complications include generator failure (extremely rare), and lead failure (less rare). Most of these complications are uncommon, and can be prevented by simple manoeuvres. Nonetheless, there are some complications related to pacemaker system disfunctions which may cause life-threatening complications. Pacemaker malfunctions may be corrected with accurate, timely diagnosis, but will not be discussed in this chapter.

Pacemaker complications can be divided into acute (immediate) or chronic according to implantation time (or date); lead or pocket complications according to the site of complication; and implantation or system failures, according to aethiology (Table 1). The most common and frequent complications are those related to implantation. Pacemaker implantation is a safe procedure in experienced hands, but these complications can be caused even by experienced operators. By following the suggested maintenance schedule, physicians usually detect pacemaker problems before they become serious. However, it remains important for patients to be aware of the symptoms of bradycardia, symptoms that might indicate a pacemaker malfunction. Once again, these symptoms include weakness, easy fatigability, lightheadedness, dizziness, and loss of consciousness. Patients experiencing any of these symptoms should notify their doctor. Especially following complications such as lead dislodgment, pnemothorax, lead indection, and cardiac tamponade, the patients must be informed about these symptoms.

The frequency of complications varies between $10 \%$ and $59 \%$ for the procedures. This wide range exists due to the common problem of defining complications. In some papers, a localized infection or rib fracture is defined as a minor complication. However, in other papers, these complications are not even recorded. If the pacemaker lead becomes dislodged on day 4, is this a complication or not? Some authors say yes; others no. This ambiguity leads to a great challenge when trying to compare papers. In this chapter, we will try to discuss these problems systematically and transparently. 
Significant reductions in frequency of complications related to pacemakers have been noted due to emerging technological developments, ever increasing experience and patient education.

\begin{tabular}{|l|l|}
\hline \multicolumn{2}{|c|}{ Complications } \\
\hline \multicolumn{1}{|c|}{ Pocket complications } & \multicolumn{1}{c|}{ Lead complications } \\
\hline Pocket hematoma & Acute perforation \\
\hline İnfection & Dislodgement \\
\hline Erosion & Infection \\
\hline Migration of pacemaker & Vein thrombosis \\
\hline Twiddler's syndrome & Migration \\
\hline
\end{tabular}

Table 1. Classification of pacemaker complications.

\section{Complications related to the implantation procedure}

Several lead-related complications deserve attention, including lead dislodgement, pneumothorax, loose connector pin, conductor coil (lead) fracture, and insulation break.

\subsection{Lead dislodgement}

Pacing lead displacement and dislodgement is a relatively common problem and can occur in 5-10\% of the patients (National Pacemaker and ICD database, 2001). Historically, the most common complication of transvenous pacing has been lead dislodgement. The leads can displace within chambers or out of chambers and should be suspected if the wire appears too taut or too redundant. Leads may dislodge from the initial implant site in the first few days to few weeks following the implantation. Active and passive fixation mechanism of leads help prevent this complication. Atrial lead dislogement is slightly more common than it is for venrricular leads. Acceptable dislodgmenet rates should be probably be less than $1 \%$ for ventricular leads and no more than 2-3\% for atrial leads (Braunwald). Although passive fixation leads are stable in the atrial appendage, active fixation leads are necessary to prevent dislodgement in patients with prior cardiac surgery. Lead dislodgement may result in an increase in pacing thresholds, failure to capture, or failure to sense. Lead dislodgement may be radiographically visible or it may be microdislodgement, where there is no radiographic change in position, but there is significant increase in pacing threshold and/or decline in the electrocardiogram amplitude (Figure 1). Also migration of a dislodged lead out of the heart may be associated with thromboembolic complications if it is not detected acutely. 


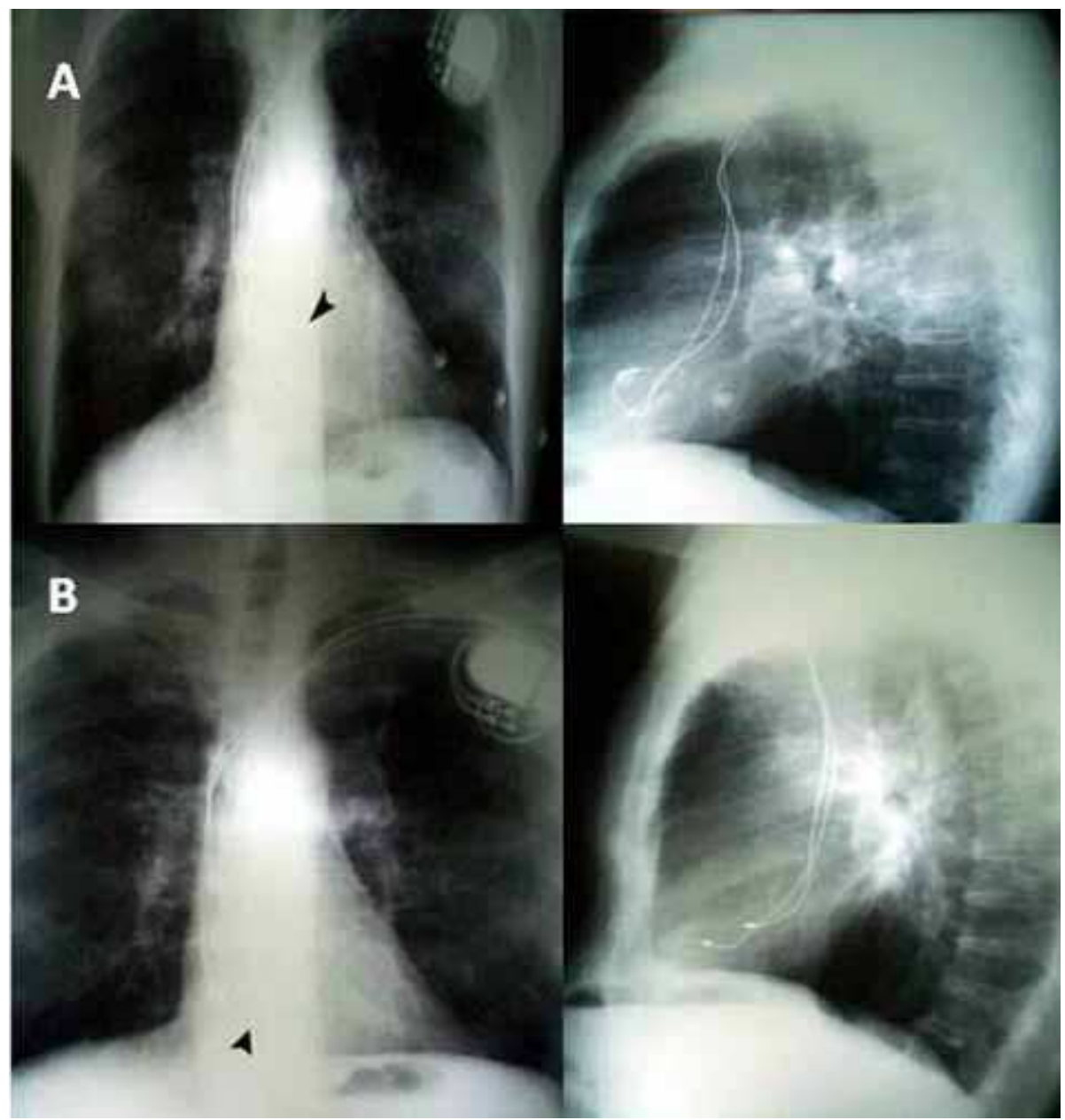

Fig. 1. Top (A): Postero-anterior and lateral chest X-ray films obtained 24 hours after pacemaker implantation showing atrial lead tip (arrow head) inside the right atrial appendage; Bottom (B): Radiograph obtained three months later showing displacement of atrial lead (arrow head) towards tricuspid annulus.

\subsection{Pneumothorax, hemothorax, and air embolism}

This complication occurs uncommonly and is directly related to operator experience, the difficulty of the subclavian vein puncture, and is almost eliminated using the cephalic cutdown technique. The incidence of pneumothorax ranges from 1.6 to $2.6 \%$ with $80 \%$ of thesecases requiring chest tube placement if $>10 \%$ of the lung is involved, the patient has continued repiratory distress, or hemo-pneumothorax is present (Grier et al., 1990). A pneumothorax estimated to involve $<10 \%$ of the pleural space can probably be observed without chest tube placement. This can occur from inadvertent puncture and laceration of the subclavian vein or the subclavian artery or the lung. 
If a pneumothorax develops, it may manifest during the pacemaker procedure or as late as 48 hours after implantation (Figure 2). However, these traditional comparisons may become obsolete as the axillary vein cannulation technique (Martin et al., 1996) threatens to eliminate this controversery. To minimize the risk of pneumothorax, fluoroscopic guidance of the subclavian puncture should be used together with careful technique, or to use safe sheats with one-way mechanism which also reduces risk of other potential complications (hemothorax, inadvertent arterial puncture, air embolism, arteriovenous fstula, thoracic duct injury, and brachial plexus injury). Often pneumothorax is asymptomatic and noted on routine follow-up plain chest radiograph.

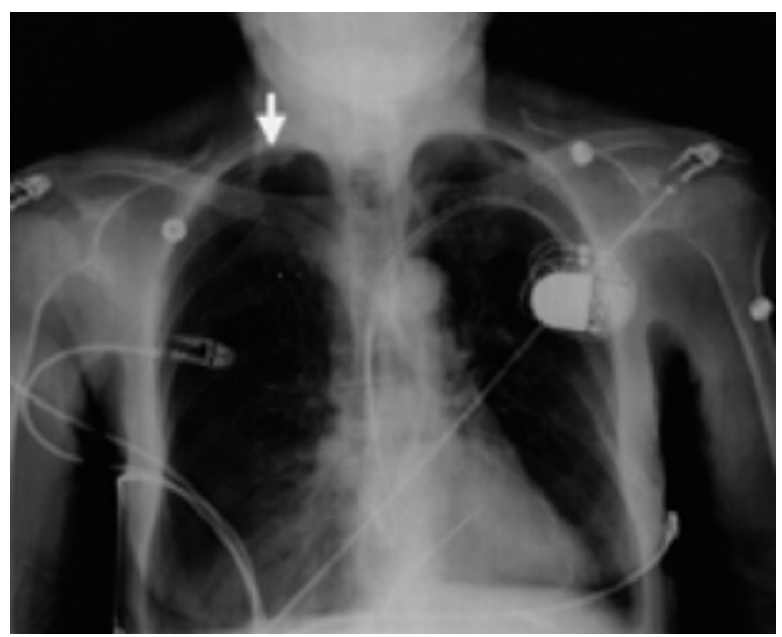

Fig. 2. Chest $\mathrm{X}$-ray showing right pneumothorax (arrow) $8 \mathrm{~h}$ after placement of a left-sided permanent dual chamber pacemaker.

Location of pneumothorax, i.e. ipsilateral or contralateral was reported. Contralateral pneumothorax to the site of the pacing system has been reported, which was secondary to an unsuccessful attempt on that side (Sebastian et al., 2005).

In the setting of pneumothorax, pneumopericardium can occur when air dissects through the pulmonary parenchyma along the perivascular sheats back to the hilum. The pericardium is weakest at its reflection surrounding the ostia of the pulmonary veins and air can leak into the pericardial space at this location. In haemodynamically stable patients, CT scan of the chest is investigation of choice (Figure 3). In unstable patients emergency echocardiography may be useful to identify pericardial effusion (Burney et al., 2004).

Deep inspiration at the time of central venous access may cause significant air to be drawn into the venous system due to the physiological negative pressure developed. Three obligatory conditions need to coexist for pulmonary air embolism to occur: (1) there must be a source of gas/air; (2) an open access to the venous system; and (3) a pressure gradient between the source of gas/air and the venous sytem (Yeakel, 1968). It can be prevented through operator care and using introducers with hemostatic valves. The diagnosis is obvious because it is heralded by a hissing sound as the air is sucked in and with the fluoroscopic confirmation that follows (Figure 4). 100\% oxygen should be administered along with ionotropic support in some cases. Aspiration of the embolus from the right heart has also been successful. However, usually no therapy is required, as the air is filtered and consequently absorbed in the lungs. 


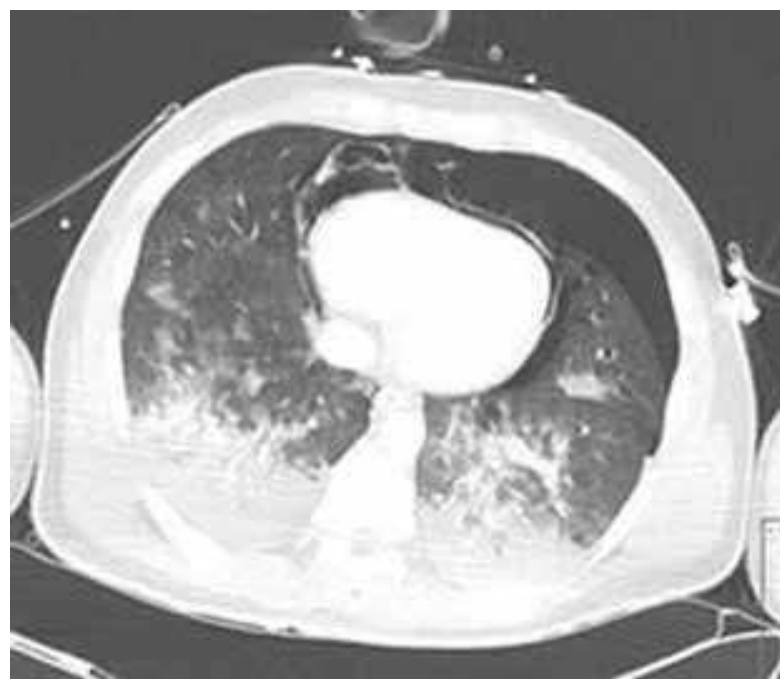

Fig. 3. CT scan of the chest showing massive hemothorax, pneumothorax, and pneumopericardium.

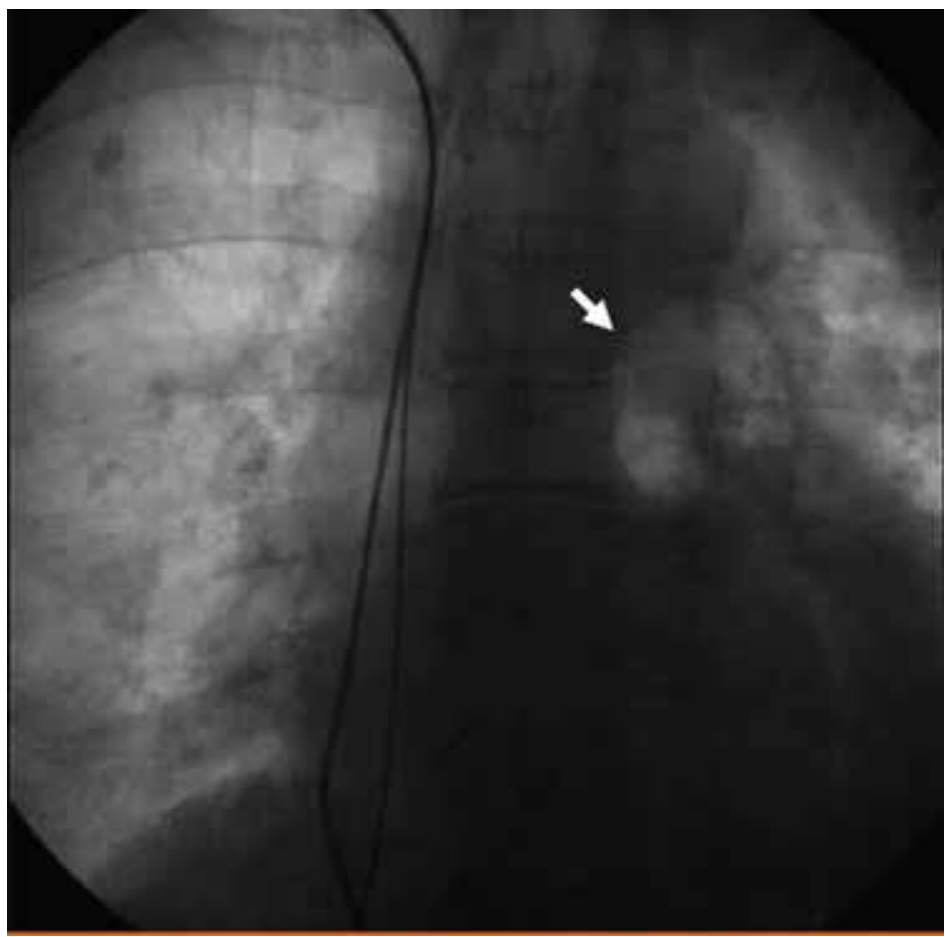

Fig. 4. Chest $\mathrm{X}$-ray showing a large air embolus (arrow) in the main pulmonary artery bifurcation during permanent pacemaker implantation. 
Three main issues are important in diagnosis and management of this problem: (1) deep inspiration should be avoided in the presence of an open intravenous route; (2) when using a peal-away sheath, temporarily close the intravenous entrance route before inserting the lead; and (3) snoring may be an alarm sound! (Turgeman et al., 2004).

\subsection{Lead perforation}

Myocardial perforation during lead placement is an uncommon but potentially serious complication. The published incidence of this complication varies from 0.4 to $5.2 \%$, but nowadays it is usually lower than $1 \%$ (Danik et al., 2007; Carlson at al., 2008). The use of active fixation leads is associated with higher rate of cardiac perforations (Geyfman et al., 2007). Recently, several reports on increased rate of cardiac perforations with both active and passive defibrillation leads of one model have published (Satpathy et al., 2008).

The definition of a subacute and delayed myocardial perforation is normal X-ray and electrical parameteres (R-wave sensing, pacing threshold, impedance) 24 hours after implantation without clinical signs of perforation and the diagnosis of lead perforation by Xray (Figure 5), echocardiography, or computed tomography 5 days to 1 month (subacute) or $\geq 1$ month (delayed) after implantation. Delayed lead perforation (occuring more than 1 month after implantation) is a rare complication. Its pathophysiology and optimal management are currently unclear. Delayed lead perforations are fewer in number than acute lead perforations in the literature (Velavan et al., 2003; Khan et al., 2005). Delayed lead perforations have caused chest pain, hemopneumothorax and pneumothorax, but no cases of cardiac tamponade or death have been documented (Trigano \& Caus, 1996). One of the distinguishing features of delayed lead perforation as opposed to acute lead perforation is the decrease or absence of cardiac tamponade or death.

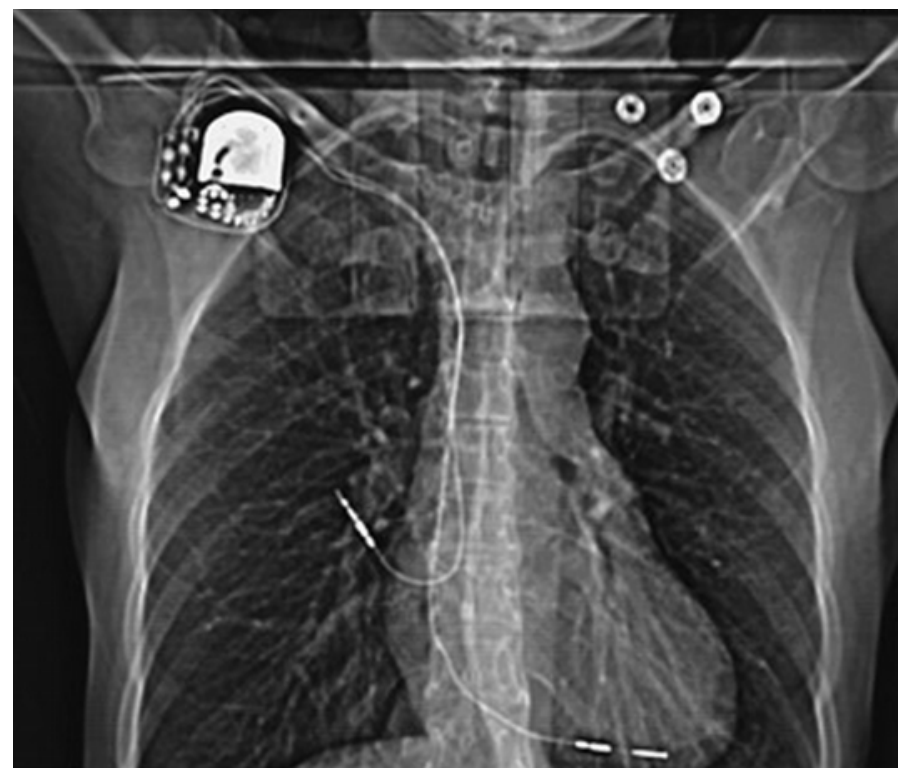

Fig. 5. Chest $X$-ray demonstrating severe lead perforation due to implantable cardioverterdefibrillator implantation. 
Surprisingly, the perforation rate did not differ significantly between the pacemaker and ICD implantation. Hirschl et al. found that atrial leads perforated more frequently than ventricular leads, and ICD leads perforate more frequently than ventricular pacemaker leads (Hirschl et al., 2007). The factors that may influence the perforation ratio rate could be divided into three groups:

1. Lead design (diameter, fixation mechanism, construction of the lead tip, pre-shaped Jcurve),

2. Physicians' experience and training level,

3. Patient-related factors

Clinical presentations of late perforation may vary widely from asymptomatic patients to sudden cardiac death. This highlights the importance of a high degree of suspicion and the need of proper diagnostic methods. Diagnosis of a perforation is usually based on clinical findings. Echocardiographic imaging may suggest perforation, but unless the lead is completely through the myocardium, the study may be inconclusive. More recently, CT has been reported as a method of diagnosing myocardial perforation (Figure 6). Diagnosis of perforation is made using four signs:

1. Decrease in arterial blood pressure without any other explanation,

2. Decrease in pulsatility of the cardiac silhouette as monitored by fluoroscopy,

3. Increased size of the cardiac silhouette,

4. Abnormal position of the transvenous lead too far out toward the left ventricle along the pericardial outline

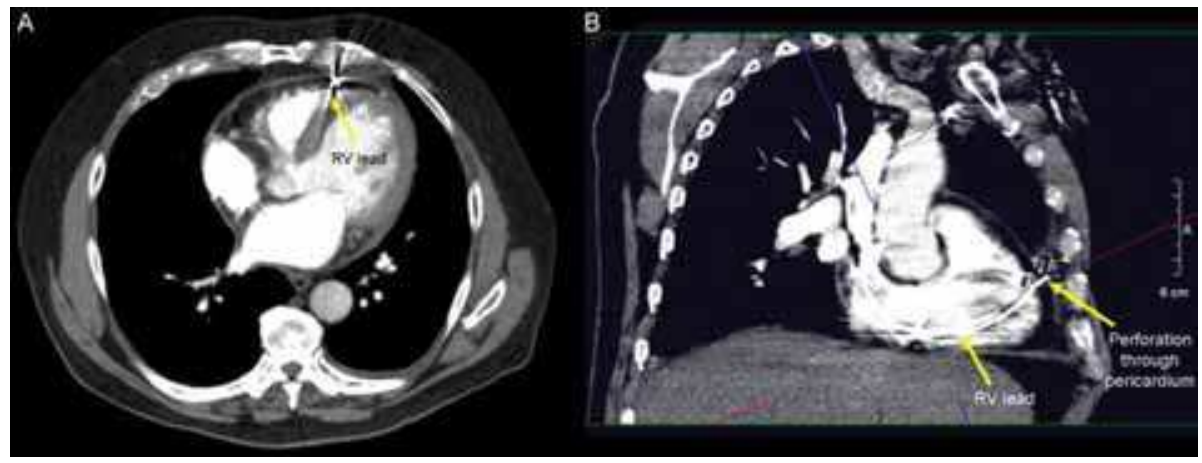

Fig. 6. CT images of the thorax emonstrating right ventricular (RV) lead position and cardiac perforation by RV electrode.

Currently, approprate management of lead perfroration is uncertain. Perforation associated with hemodynamic compromise must be dealt with as an emergency. The lead may perforate any of the great veins, the atria, or ventricle during the implant procedure. This complication almost always occurs in the cardiac chamber on lead manipulation or fixing a screw in lead, and consequently bleeds into the pericardial space. A most devastating manifestation is cardiac tamponade, which requires prompt diagnosis and percutaneous pericardiocentesis, possibly followed by surgical intervention if the bleeding persists. Rarely, trauma to the great veins above the pericardial reflection may cause bleeding directly into the mediastinum. This is much more of a concern when extracting leads than implanting them and is an emergent indication for open chest surgery. Furhermore, the management described in the literature depends on the lead type. 
Another late complication of lead perforation occurs at the time of lead extraction if required. While active fixation leads have mostly been extracted transvenously after retraction of the coil, extraction of passive fixaton leads causes concern because of the bulky tip of the lead may cause tissue damage during removal. Khan and colleagues recommend that lead extraction should be done in the operating room under TEE observation with cardiac surgery backup (Khan et al., 2005).

Overall, our experience with delayed lead perforations with lead perforations has provided a management scheme as outlined above that incorporates clinical history, chest X-ray, and device interrogation among other diagnostic tools (echocardiography, CT etc.).

\subsection{Extracardiac stimulation}

Extracardiac stimulation usually involves the diaphragm or pectoral or intercostal muscles. Diaphragmatic stimulation may be caused by direct stimulation of the diaphragm (usually stimulation of the left hemidiaphragm) or stimulation of the phrenic nerve (usually stimulation of the right hemidiaphragm). Diaphragmatic stimulation occuring during the early postimplantation period may be caused by microdislodgment of the pacing lead. This phenomenon is most commonly in patients with LV coronary vein branch lead placement for biventricular stimulation. During implant, high-output pacing at maximal voltage and pulse width should be tested routinely to avoid diaphragmatic stimulation. Stimulation can be minimized or alleviated by decreasing the voltage output or pulse width, or both, but an adequate pacing margin of safety must be maintained after the output parameters are decreased. If the problem cannot be resolved by reprogramming the pacemaker output, lead repositioning will be required at the moment.

Pectoral stimulation may be due to incorrect orientation of the pacemaker with its active surface in contrast with the muscle or a current leak from a lead insulation failure or exposed connector.

\subsection{Venous thrombosis and superior vena cava syndrome (SVCS)}

Venous thrombosis occurs early or late after pacemaker implantation in $30 \%$ to $50 \%$ of patients and may remain asymptomatic because of the development of venous collaterals (Oginosawa et al., 2002). Manifestations vary from usually asymptomatic, acute symptomatic thrombosis, and even SVCS (Mazzetti et al., 1993). Venous complications of pacemaker/ICD system implantation rarely cause immediate clinical problem. Only a few percent $(1-3 \%)$ of patients with severe stenosis or occlusion of the deep veins of an upper extremity become symptomatic (Stoney et al., 1976; Crook et al., 1977).

A few factors were proposed as predictors of severe venous stenosis/occlusion: a) presence of multiple pacemaker leads (compared to a single lead), b) use of hormone therapy, c) personal history of venous thrombosis, d) the presence of temporary wire before implantation, e) previous presence of a pacemaker (ICD as an upgrade) and f) the use of dual-coil leads. The presence of arm swelling, collateral veins on the arm, thorax or abdomen and possible associated facial suffision, cyanosis or edema with head and neck discomfort are classical symptoms. Routine preoperative venography to detect has been advocated before all device lead revision cases, so as alternative access can be considered (Spittell \& Hayes, 1992).

Different management approaches should be used, depending on the time since onset of stenosis/thrombosis, its location, and the presence of symptoms. Asymptomatic patients are 
usually not treated because their disease is silent and often undetected. Symptomatic patients who develop venous thrombosis should be treated promptly. Specific treatment depends on thrombosis or fibrosis being causative and varies from heparin followed by warfarin or thrombolysis to percutaneous angioplasty or an open surgical procedure. Surgery is always the last resort, reserved for patients with symptomatic occlusions that do not respond to treatment with anticoagulation or have contraindications to endovascular procedure (Rozmus et al., 2005).

A rare associated complication is pulmonary thromboembolism that is potentially lifethreatening. The presence of pulmonary embolism in a patient with a device should be arouse the suspicion of thromboic pacemaker (or ICD) lead source (Phibbs \& Marriott, 1985).

\subsection{Twiddler syndrome}

Displacement of pacemaker leads due to twisting of the box on part of the patient is called Twiddler's syndrome, first described in 1968 (Nicholson et al., 2003).Twiddler syndrome that causes device malfunction is a rare complication in patients with an implantable cardioverter defibrillators (ICD) (Fahraeus \& Höijer, 2003). Twisting of the pulse generator within the device pocket may cause the dislocation of the lead, diaphragmatic stimulation, and loss of capture (Figure 7). The prevelance of this syndrome is $0.07 \%$ (Gungor et al., 2009). Classically, Twiddler syndrome occurs in obese women with loose, fatty subcutaneous tissue and is characterized by rotation of pulse generator on its long axis with subsequent coiling of pacemaker leads (Bhatia et al., 2007). Other risk factors are mental disorders, female sex, and the small size of the implanted generator with a large pocket (Cardall et al., 1999). This disorder may induce lead dislodgement or lead fracture and cause life-threatening symptoms in case of pacemaker dependency. When the pulse generator is rotated along the transverse axis it is referred by us as the Reel sundrome, a variant of Twiddler syndrome (Camero-Varo et al., 1990).

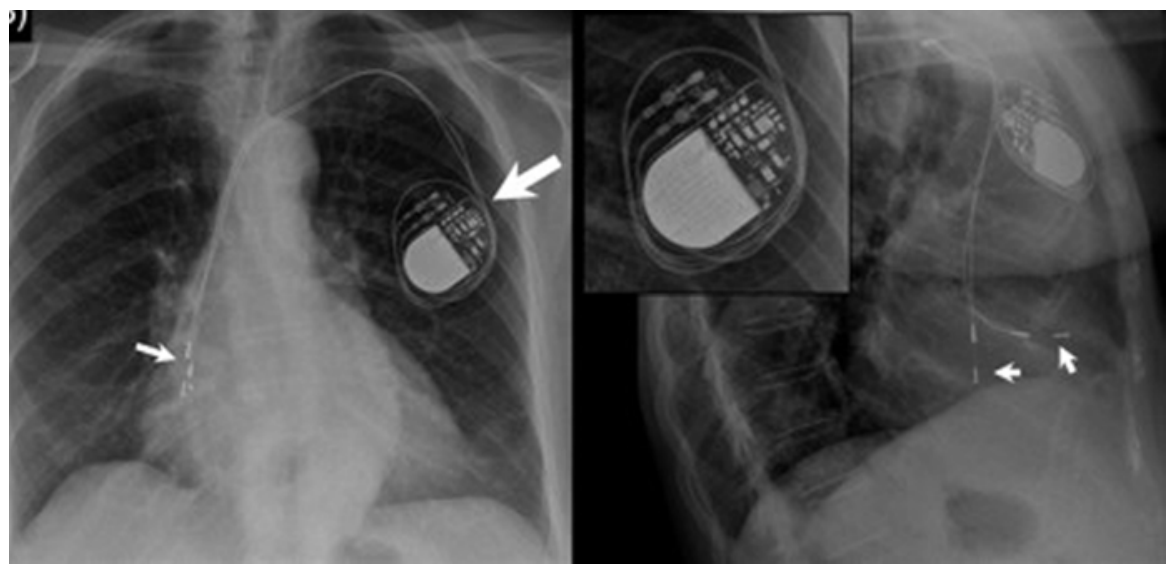

Fig. 7. Pacemaker Twiddler syndrome. Postero-anterior and lateral chest X-ray showing displacement of both leads, especially the ventricle one, retracted and floating in the right atrium (arrows).

In Twiddler syndrome, electrocardiography shows failure of capture and the chest radiography reveals the dislodged and twisted leads (Pereira et al., 1999). Hypoperfusion 
symptoms such as fatigue, tiredness, confusion, presyncope, and syncope may be observed (Cardall et al., 1999). If the problem has occured because of pacemaker migration or poorly fashioned pacemaker pocket, the pocket should be revised. As an inappropriate ICD therapy may be proarrhythmic and may lead to sudden cardiac death, Twiddler syndrome should be considered in patients with ICD who had resistant ventricular arrhythmias and abdominal pulsation. To avoid this life-threatening complication of ICD implantation, we should take care to limit the pocket size, suture the device to the fascia, and instruct the patients not to manipulate their device pockets.

\subsection{Postpacemaker implant pericarditis}

Pericarditis is an uncommon but potentially serious complication following a pacing system implantation. Pericarditis has been reported as a complication of pacemaker implantation associated with the use of active- and passive-fixation leads (Greene et al., 1994). It appeared to occur significantly more often when active-fixation atrial leads were used, affecting $5 \%$ of implants in this study. Active-fixation atrial leads have lower early dislodgement rates and are easier to remove after chronic placement. However, because the atrial wall is thin, these leads may be more likely to perforate the myocardium and cause pericarditis. Perforation through the right ventricular wall is also possible though the wall thickness is greater than in the atrium, and thus presumably less likely to occur. Alternatively, traumatic inflammation extending from the lead screw and traversing through the myocardium to the pericardium is also possible mechanism (Sivakumaran et al., 2002). Patients developing pericarditis postpacemaker implantation should be followed closely due to the risk of cardiac tamponade. If there is no evidence of tamponade or symptomatic pericardial effusion, it is reasonable initially to treat the patient conservatively, i.e., observation and pain medications. Anti-inflaammatory medications, e.g., nonsteroidal or steroids, may relieve symptoms. However, if the medications cannot be withdrawn without symptom recurrence, it may be necessary to remove and reposition the leads.

\section{Pocket-related complications}

\subsection{Pocket hematoma}

Hematomas occuring at the pacemaker pocket site can vary from a small ecchymosis to large and tense swelling (Figure 8). The risk of haematoma is increased in patients taking antithrombotic or anticoagulant drugs (Goldstein et al., 1998). Most small hematomas can be managed conservatively with cold compress and withdrawal of antiplatelet or antithrombotic agents. In patients requiring oral anticoagulants (warfarin), to take INR of about 2.0 at the time of implantation is safe (Belott \& Reynolds, 2000). Unfractionated heparin or low-molecular-weight heparin are always discontinued prior to device implant and ideally avoided for a minimum of 24 hours post implantation. Administration of anticoagulants can be resumed within $48-72 \mathrm{~h}$ after implantation if there is no evidence of substantial hematoma formation. Occasionally, large hematomas that compromise the suture line or skin integrity may have to be surgically evacuated. Evacuation of the hematoma is very rarely needed ( $<0.5 \%$ of cases). Needle aspiration increases risk of infection and should not be done. Aspiration should be considered only if there is continued bleeding, potential compromise of the suture line or skin integrity, or pain refractory analgesics (Pavia \& Wilkoff, 2001). 


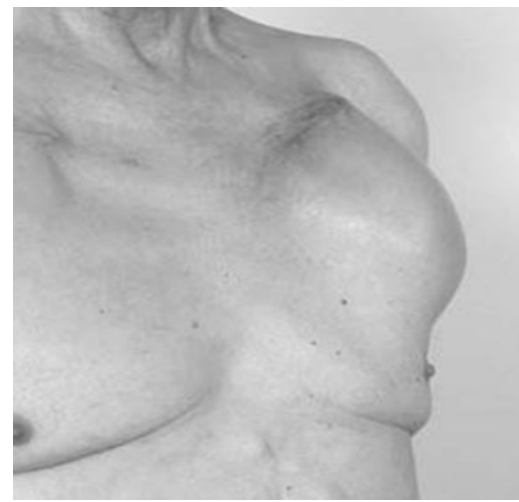

Fig. 8. Pocket hematoma

In patients who require therapeutic anticoagulation, heparin should be delayed for at least 24 to 48 hours after implantation to avoid bleeding complications.

\subsection{Wound pain}

Patients should be told to expect some local discomfort at the pacemaker implantation site. For several reasons, a patient could experience a painful pacemaker site, commonly called "painful pocket", and the complaint should be taken seriously. The diferential diagnosis includes:

- Infection

- Pacemaker implanted too superficially

- Pacemaker implanted too laterally

- Pacemaker allergy

Minor wound pain is expected after device implantation, almost always controlled with simple analgesia. In general, the pre-pectoral site is extremely well-tolerated, i.e., the pacemaker pocket should be formed in the prepectoralis fascia. If it is placed anterior to the adipose layer, i.e., within subcutaneous tissues, significant pain may result. If the pacemaker is positioned too laterally, impingement on the axillary space may cause discomfort. Continuing pain will usually improve or manifest an obvious infection eventually. However, pain that initially improves then recurs or occurs temporarily remote from the implant may suggest infection even in the absence of any outward localizing signs, and consequently may necessitate surgical exploration or even empirical removal and reimplant at another site. If a painful pocket is explored for any reason, specimens for culture should be obtained.

\subsection{Skin erosion}

Skin erosion is caused by the underlying pacemaker generator has been reported several times as a complication of pacemaker implants (Kiviniemi et al., 1999). This is the most common late complication of pacemaker implantation abd its incidence has been estimated around $0.8 \%$ (Harcombe et al., 1998).

Factors predisposing skin erosion are the tissue fragility in old-age patients, the presence of a thin subcutaneous fat layer and abrasive action exerted on the skin from external agents (Figure 9). Other common causes of skin erosion are possible infections of the site and the 
pressure exercised from the device on the subcutanous tissue (Harcombe et al., 1998). Griffith et al. concluded that if pacemaker erosion is not caused by infection it can be successfully managed by ipsilateral re-implantation, i.e., revision and this is a financially advantageous solution (Griffith et al., 1994). If true eroison occurs, the system is considered contaminated and current opinion favors removal of the generator and leads to the clean site (Shapiro et al., 2004; Guiseppe et al., 2009). It is crucial to identify early signs of erosion before the hardware breaks the skin. If the skin is intact, surgical revision of the pocket is often all that is needed to protect the hardware from contamination and infection.

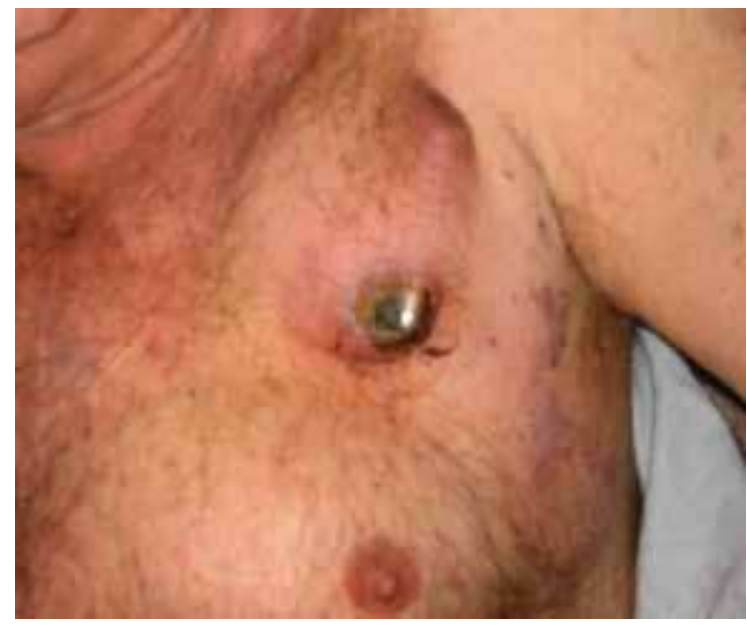

Fig. 9. Erosion of the automated implantable cardioverter-defibrillator (AICD).

\subsection{Allergic reactions to the pacemaker component}

Pacemaker component allergy is a relatively uncommon cause of erithema and pain at the site of an implanted pacemaker. Diagnosis is often postponed and/or misinterpreted as a skin infection. Allergies to multiple pacemaker components have been well described (Hayes \& Loesl, 2002). Most reactions occur between several weeks to a few months after implantation. The diagnosis should be suspected in cases of skin reaction following pacemaker implantation that does not respond promptly to antibiotic treatment. When infection has been ruled out, it may still be difficult to make a diagnosis of a pacemaker component allergy, for several reasons. Because a true allergic reaction to a pacemaker component is rare, the clinician may simply fail to include it in the differential diagnosis. Also, the allergy testing required is sophisticated and must be done correctly. Important, corticosteroid use can result in skin anergy and in a false-negative skin test.

Allergies to various pacemaker components have been reported, including titanium (Peters et al., 1984; Yamauchi et al., 2000), polychloroparaxylene (Iguchi et al., 1997), nickel (Landwehr \& van Ketel, 1983), polyurethane (Abdallah et al., 1994), epoxy (Andersen, 1979), mercury (Brun \& Hunziker, 1980), cadmium (Laugier et al., 1975), chromate (Laugier et al., 1975), silicone (Raque \& Goldschmidt, 1970), and cobalt (Tilsey \& Rotstein, 1980).

Once an allergy has been demonstrated, it is imperative that the component either be eliminated from subsequent pacing systems or be completely coated. The only definitive treatment is removal of the allergens. Some patients may respond to topical corticosteroids 
(Viraben et al., 1995). But replacement of the device for one that is free of allergenic components or wrapped with an inert coating is the treatmnet choice (Déry et al., 2002).

\subsection{Device-related infections}

Despite improvements in the design and implantation techiques, infection of the cardiac devices remain a serious problem. The first reports on infective complications after permanent endocardial stimulation were published in the 1960s. The reported incidence of pacemaker-related infection ranges from $0.5 \%$ to $6 \%$ in early series (Hill, 1987; Kearney et al., 1994). Recently, Uslan et al. reported the overall incidence of device-related infection to be 1.9 per 1000 device-years (Uslan et al., 2007). In the study by Aggarwal et al (Aggarwal et al., 1995), the incidence of infections in patients with dual-chamber (1\%) compared with single-chamber devices $(0.82 \%)$ was similiar, whereas in the study by Chauan et al. (Chauan et al., 1994), wound infections developed in $0.6 \%$ of patients with single-chamber versus $2.1 \%$ of patients with dual-chamber devices. This infection is associated with substantial morbidity, mortality, and financial cost (Sohail et al., 2007). The mortaility of persistent infection when infected leads are not removed can be as high as 66\% (Rettig G, Doenecke et al. Complications with retained transvenous pacemaker electrodes. Am Heart J 1997; 98:587594). In a study by Sohail et al (Sohail et al., 2007) generator pocket infection $(69 \%)$ and device-related endocarditis $(23 \%)$ were the most common clinical presentations of infection.

Several factors have been anecdotally reported (Eggimann et al., 2000) to be associated with an increased the risk of PPM infection, inckuding diabetes mellitus, malignancy, operator inexperience, advanced age, corticosteroid use, anticoagulation, recent device manipulation, chronic renal failure, and bacteremia from a distant focus of infection. Pacemaker endocarditis is most commonly complicated by tricuspid valve vegetations (Bortolotti et al., 1993), tricuspid regurgitation, and occasionally by secondary pulmonary embolism (Klug et al., 1997). Also, the presence of multiple leads is a potential cause for central venous thrombosis, and has been thought to increase the risk of device infection by serving as a nidus for seeding of bacteria (Howarth et al., 1998).

Device infection is defined as either: (a) deep infection - infection involving the generator pocket and/or the intravenous portion of the leads, with or without bacteremia, requiring device extraction or (b) superficial infection - characterized by local inflammation, involving the skin but not the generator pocket, and treated with oral antibiotics. Also Charles Byrd divided pacemaker-related infections into the following groups (Ellenbogen et al., 2007)

- endocarditis;

- inflammation of myocardial tissue;

- infected vegetations;

- infected implanted foreign bodies;

- bacteremia without signs of endocarditis;

- local infections of subcutaneous tissue;

- chronic infections limited to the pocket area;

- $\quad$ superinfection of pacemaker pocket area;

- chronic pocket infection with granulation tissue

Early infections are most commonly caused by Staphylococcus aureus and late infections most commonly by Staphylococcus epidermidis, although infections by Staphylococcus lugudensis (Anguera et al., 2005), streptococcus bovis, mitis, and sanguis, pseudomonas (Laguno et al., 1998), enterococci and fungi and even Mycobacterium fortuitum (Sharma et al., 2005) have been described (Figure 10). 


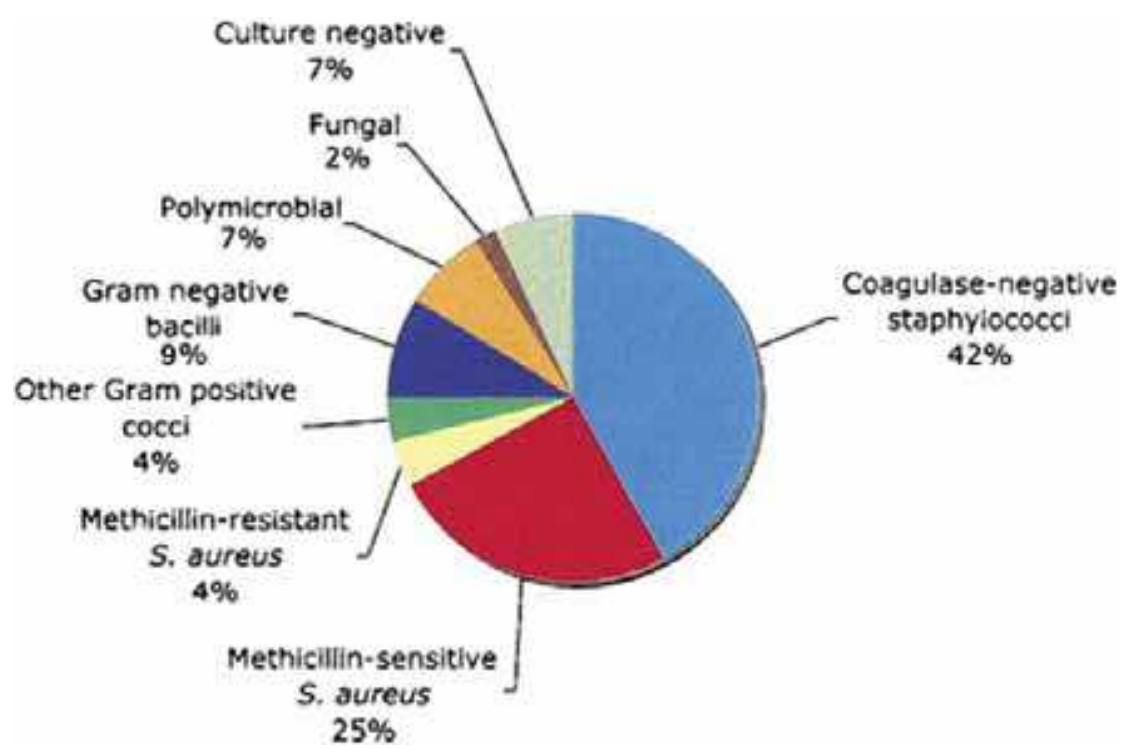

Fig. 10. Microbiology of permanent pacemaker/ICD infections (With permission of: Sohail MR, Uslan DZ, Khan AH et al. Management and Outcome of Permanent Pacemaker and Implantable Cardioverter-Defibrillator Infections. J Am Coll Cardiol 2007; 49:1851-9).

Pacemaker infection must be recognized and be treated properly. It may appaer as:

- Local inflammation and abscess formation in the area of the pulse generator pocket

- Erosion of part of the pacing system through the skin with secondary infection

- Fever associated with positive blood cultures with or without a focus of infection elsewhere

The most common clinical presentation is infection around the generator; septicemia is uncommon mode of presentation.

There is general consensus that once there is pacemaker pocket or lead infection, removal of the whole pacemaker systme followed by a course of appropriate antibiotics results in the best prospect for long term eradication of infection. Antibiotic prophylaxis has been routinely prescribed to prevent the occurence of this complication; however, there is insufficient evidence that this strategy is benefical. In a study by de Oliveira et al (de Oliveira et al., 2009) found that antibiotic prophylaxis (single dose of $1 \mathrm{~g}$ of cefazolin) significantly reduces infectious complications in patinets undergoing pacemaker or cardioverter-defibrillators. When pacemaker lead or pocket infection is complicated by vegetations on the leads, heart valves or chamber endocardium or when there is secondary pulmonary embolism, removal of the entire device is more urgently indicated. The main recommendation is in favor of if there is vegetations that might obstruct main pulmonary artery should have removal under cardiopulmonary bypass (Tascini et al., 2006; Ruttman et al., 2006; Kaul et al., 2009).

The duration of antimicrobial treatment for cardiac device infections (CDI) depended on the clinical presentation and the causative agent. In a large case series from the Cleveland Clinic Foundation (Chua et al., 2000), the median duration of antibiotic treatment in CDI cases with pocket infection and those with bacteremia was 26 days and 41 days, respectively. An 
algorithm for management of the patient with an infected pacing or ICD system is shown in (Figure 11). This algorithm also demonstrates the timing and need of a replacement device. Guidelines suggested by Mayo Clinic for diagnosis and management of device infections are listed in (Table 2).

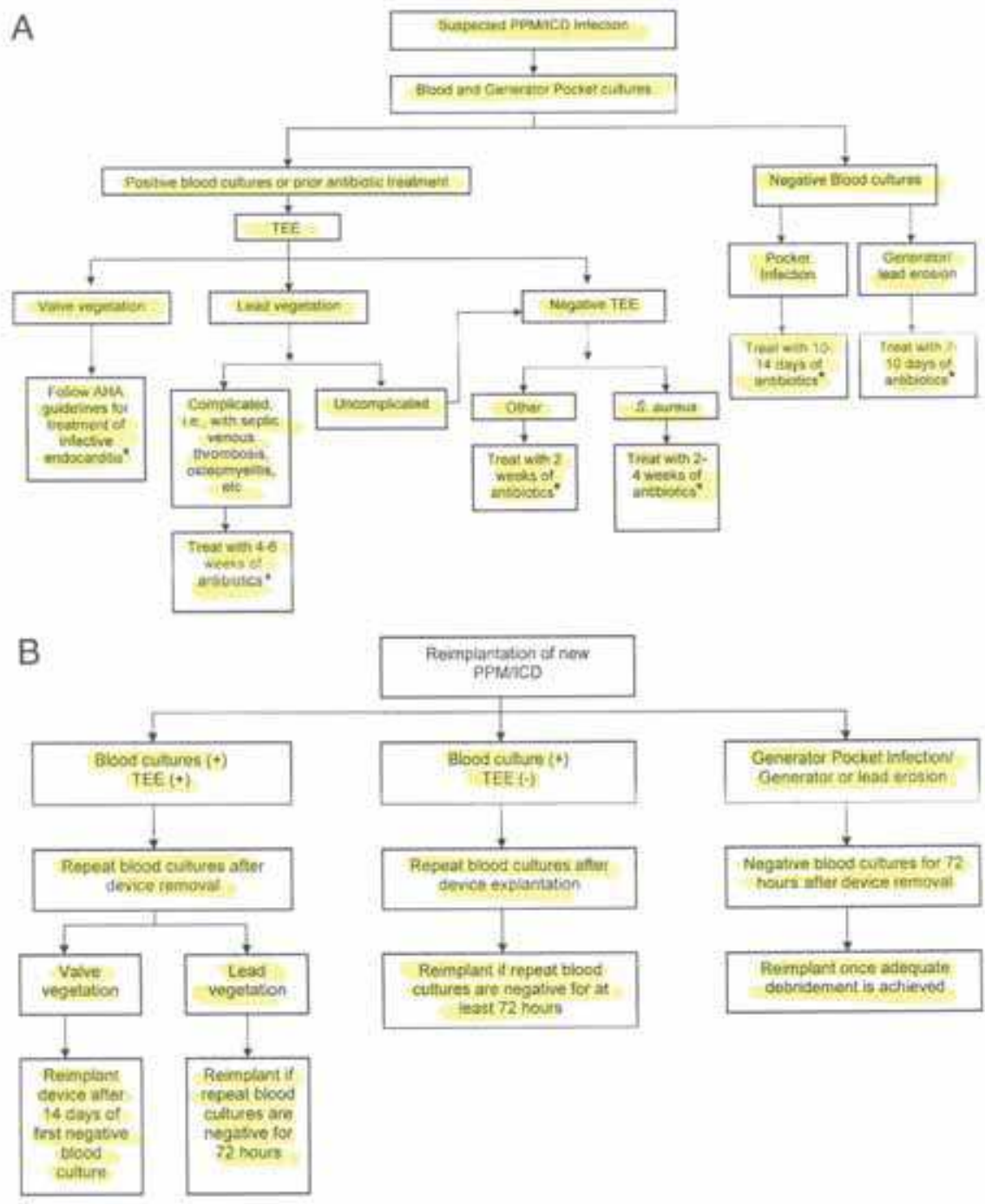

Fig. 11. Mayo Clinic algorithm of cardiac device infection management. (A) Treatment algorithm based on blood and generator pocket cultures. This algorithm applies only to the patients with complete explanation of the implanted system. (B) Algorithm for reimplantation of new pulse generator. (With permission from Sohail MR, Uslan DZ, Khan $\mathrm{AH}$, et al. Management and outcome of permanent pacemaker and implanted cardioverterdefibrillator infections. JACC 2007; 49:1851-9). 


\begin{tabular}{|c|c|}
\hline 1. & tion. \\
\hline 2. & Generator tissue Gram stain and culture and lead tip culture should be obtained. \\
\hline & $\begin{array}{l}\text { Patients who either have positive blood cultures or have negative blood cultures but } \\
\text { had recent antibiotics before obtaining blood cultures should have a transesophageal } \\
\text { echocardiogram (TEE) to assess for device-related endocarditis. }\end{array}$ \\
\hline & $\begin{array}{l}\text { Sensitivity of TTE is low and is not recommended to evaluate for devvice-related } \\
\text { endocarditis. }\end{array}$ \\
\hline & $\begin{array}{l}\text { Patients with negative blood cultures and recent prior antibiotics and valve } \\
\text { vegetations on TEE should be managed in consultation with an infectious diseases } \\
\text { expert. }\end{array}$ \\
\hline & $\begin{array}{l}\text { All patients with device infection should undergo complete device removal, } \\
\text { regardless of clinical presentation. }\end{array}$ \\
\hline & $\begin{array}{l}\text { A large }(>1 \mathrm{~cm}) \text { lead vegetation is not a stand alone indication for surgical lead } \\
\text { removal. }\end{array}$ \\
\hline & $\begin{array}{l}\text { ultures should be repeated in all patients aft } \\
\text { rsistently positive blood cultures should be } t \\
\text { robial even if TEE is negative for vegetations }\end{array}$ \\
\hline & $\begin{array}{l}\text { Duration of antimicrobial therapy should also be extended to } \geq 4 \text { weeks in patients } \\
\text { with complicated infection (endocarditis, septic venous thrombosis, osteomyelitis, } \\
\text { metastatic seeding). }\end{array}$ \\
\hline & $\begin{array}{l}\text { ebridement and control of infection should also be achieved at all sites } \\
\text { olantation of a new device. }\end{array}$ \\
\hline & $\begin{array}{l}\text { Reevaluation for continued need of the device should be performed before new } \\
\text { device placement. }\end{array}$ \\
\hline & $\begin{array}{l}\text { If an infected cardiac device cannot be removed, than long-term suppressive } \\
\text { antibiotic therapy should be administered after completing an initial course of } \\
\text { treatment and securing a clinical response to therapy. Infectious diseases expert } \\
\text { opinion should be sought. }\end{array}$ \\
\hline
\end{tabular}

Table 2. Guidelines for diagnosis and management of cardiac device infections (Modified from Mayo Clinic Guidelines).

\section{References}

National Pacemaker and ICD database. UK and Ireland. Annual Report 2001 Braunwald

Grier D, Cook PG, Hartnell GG. Chest radiographs after permanent pacing. Are they really necessary? Clin Radiol 1990; 42:244-9

Martin C, Auffray JP, Saux P, et al. The axillary vein: An alternative approach for percutaneous pulmonary artery catheterization. Chest 1996; 90:694-697

Sebastian CC, Wu WC, Shafer M, Choudhary G, and Patel PM. Pneumopericardium and Pneumothorax After Permanent Pacemaker Implantation. PACE 2005; 28:466-468

Burney K, Burchard F, Papouchado M, Wilde P. Cardiac pacing systems and implantable cardiac defibrillators (ICDs): a radiological perspective of equipment, anatomy and complications. Clin Radiol 2004; 59:699-708

Yeakel AE. Lethal air embolism from plastic blood-storage container. JAMA 1968; 204:175177 
Turgeman Y, Antonelli D, Atar S, and Rosenfeld T. Massive Transient Pulmonary Air Embolism during Pacemaker Implantation under Mild Sedation: An Unrecognized Hazard of Snoring. PACE 2004; 27:684-685

Danik SB, Mansour M, Singh J, Reddy VY, Ellinor PT, Milan D et al. Increased incidence of subacute lead perforation noted with one implantable cardioverter-defibrillator. Heart Rhythm 2007; 4:439-42

Carlson MD, Freedman RA, Levine PA. Lead perforation: incidence in registries. Pacing Clin Electrophysiol 2008; 31:13-5

Geyfman V, Storm RH, Lico SC, Oren JW. Cardiac tamponade as complication of activefixation atrial lead perfrorations: proposed mechanism and management algorithm. Pacing Clin Electrophysiol 2007; 30:498-501

Satpathy R, Hee T, Esterbrooks D, Mohiuddin S. Delayed defibrillator lead perforation: an increased phenomenon. Pacing Clin Electrophysiol 2008; 31:10-2

Velavan P, Chauman A. An unusual presentation of delayed cardiac perforation caused by atrial screw-in lead. Heart 2003; 89:364

Khan M, Joseph G, Khaykin Y, Zrada K, Wilkoff B. Delayed lead perforation: A disturbing trend. Pacing Clin Electrophysiol 2005; 28:251-253

Trigano AJ, Caus T. Lead explanation late after atrial perforation. Pacing Clin Electrophysiol 1996; 19:1268-1269

Hirschl DA, Jain VR, Spindola-Franco H, Gross JN, and Haramati LB. Prevelance and Characterization of Asymptomatic Pacemaker and ICD Lead Perforation on CT. PACE 2007; 30:28-32

Oginosawa Y, Abe H, Nakashima Y. The incidence and risk factors for venous obstruction after implantation of trabsvenous pacing leads. Pacing Clin Electrophysiol 2002; 25:1605-1611

Mazzetti H, Dussaut A, Tentori C, et al. Superior vena cava occlusion and/or syndrome related to pacemaker leads. Am Heart J 1993; 125:831-837

Stoney WS, Addlestone RB, Alford WC Jr, Burrus GR, Frist RA, Thomas CS Jr. The incidence of venous thrombosis following long-term transvenous pacing. Ann Thorac Surg $1976 ; 22: 166-170$

Crook BR, Gishen P, Robinson CR, Oram S. Occlusion of the subclavian vein associated with cephalic vein pacemaker electrodes. Br J Surg 1977; 64:329-331

Spittell P, Hayes D.Venous complications after insertion of a transvenous pacemaker. Mayo Clin Proc 1992; 67:258-265

Rozmus G, Daubert JP, Huang DT, Rosero S, Hall B, and Francis C. Venous Thrombosis and Stenosis After Implantation of Pacemakers and Defibrillators. Journal of Interventional Cardiac Electrophysiology 2005; 13:9-19

Phibbs B, Marriott H. Complications of permanent transvenous pacing. N Engl J Med 1985; 22:1428-1432

Nicholson WJ, Touhy KA, Tikemeier P. Twiddlers syndrome. N Engl J Med 2003; 348:1726-7

Fahraeus T, Höijer CJ. Early pacemaker Twiddler syndrome. Europace 2003; 5:279-281

Gungor H, Duygu H, Yildiz BS, Gul I, Zoghi M, and Akin M. Twiddler syndrome as a rare cause of implantable cardioverter defibrillator malfunction. J Cardiovasc Med 2009; 10:352-353

Bhatia V, Kachru R, Parida AK, Kaul U. Twiddlers syndrome. Int J of Cardiol 2007; 116:e82 
Cardall TY, Brady WJ, Chan TC, Perry JC, Vilke GM, Rosen P. Permanent cardiac pacemakers: issues relevant to the emergency physician; part II. J Emerg Med 1999; 17:697-709

Camero-Varo A, Perez-Paredes M, Ruiz-Ros A, Gimenez-Cervantes D, Martinez-Corbalan FR, Cuberto-Lopez T. "Reel syndrome"'-a new form of Twiddlers syndrome? Circulation 1990; e45-6

Pereira PL, Trubenbach J, Farnsworth CT, Huppert PE, Claussen CD. Pacemaker and defibrillator Twiddler's syndrome. Eur J Radiol 1999; 30:67-69

Greene TO, Portnow AS, Huang SK. Acute pericarditis resulting from an endocardial active fixation screw-in atrial leads. PACE 1994; 17:21-25

Sivakumaran S, Irwin ME, Gulamhusein SS, and Senaratne PJ. Postpacemaker Implant Pericarditis: Incidence and Outcome with Active-Fixation Leads. PACE 2002; 25:833-837

Goldstein DJ, Losquadro W, Spotnitz HM. Outpatient pacemaker procedures in orally anticoagulated patients. Pacing Clin Electrophysiol 1998; 21:1730-1734

Belott P, Reynolds D. Permanent pacemaker and implantable cardioverter defibrillator implantation. In Ellenbogen K, Kay G, Wilkoff B(Eds): Clinical cardiac pacing and defibrillation, WB Saunders. Philadelphia: Saunders; 2000, 573-644

Pavia S, and Wilkoff B. The management of surgical complications of pacemaker and implantable cardioverter-defibrillators. Current Opinion in Cardiol 2001; 16:66-71

Kiviniemi MS, Pirnes MA, Eranen HJ, Kettunen RV, Hartikainen JE. Complications related to permanent pacemaker therapy. Pacing Clin Electrophysiol 1999; 22:711-720

Harcombe AA, Newel SA, Ludman PF, Wistow TE, Sharples LD, Shofield PM, et al. Late complications following permanent pacemaker implantation or elective unit replacement. Heart 1998; 80:240-244

Griffith MJ, Mounsey JP, Bexton RS, Holden MP. Mechanical, but not infective, pacemaker erosion may be successfully managed by re-implantation of pacemakers. Br Heart J 1994; 71:202-205

Shapiro M, Hanon S, Schweitzer P. A Rare, Late Complication after Automated Implantable Cardioverter-Defibrillator Placement. Indian Pacing Electrophysiol J 2004; 4:213-216

Guiseppe S, Sarubbi B, D'Alto M, Romeo E and Calabro R. Extrusion of the device: a rare complication of the pacemaker implantation. J Cardiovasc Med 2009; 10:330-332

Hayes DL and Loesl K. Pacemaker Component Allergy: Case Report and Review of the Literature. J of Intervent Cardiac Electrophysiol 2002; 6:277-278

Peters MS, Schroeter AL, van Hale HM, Broadbent JC. Pacemaker contact sensitivity. Contact Dermatitis 1984; 11:214-218

Yamauchi R, Morita A, Tsuji T. Pacemaker dermatitis from titanium. Contact Dermatitis 2000; 42:52-53

Iguchi N, Kasanuki H, Matsuda N, Shoda M, Ohnishi S, Hosoda S. Contact sensitivity to polychloroparaxylene-coated cardiac pacemaker. Pacing Clin Electrophysiol 1997; 20:372-373

Landwehr AJ, van Ketel WG. Pompholyx after implantation of a nickel-containing pacemaker in a nickel-allergic patient. Contact Dermatitis 1983; 9:147

Abdallah HI, Balsara RK, O'Riordan AC. Pacemaker contact sensitivity, clinical recognition and management. Ann Thorac Surg 1994; 57:1017-1018 
Andersen KE. Cutaneous reaction to an epoxy-coated pacemaker. Arch Dermatol 1979; 115:97-98

Brun R, Hunziker N. Pacemaker dermatitis. Contact Dermatitis 1980; 6:212-213

Laugier P, Hunziker N, Orusco M, Brun R, Reiffers J, Posternak F. Dermite de contact par pace-maker (French). Dermatologie 1975; 150:219-226

Raque C, Goldschmidt H. Dermatitis associated with an implanted cardiac pacemaker. Arch Dermatol 1970; 102:646-649

Tilsey DA, Rotstein H. Sensitivity caused by internal exposure to nickel, chrome, and cobalt. Contact Dermatitis 1980; 6:175-178

Viraben R, Boulinguez S, Alba C. Granulomatous dermatitis after implantation of a titanium-containing pacemaker. Contact Dermatitis 1995; 33:437

Déry JP, Gilbert M, O’Hara G, Champagne J, Desaulniers D, Cartier P, and Philippon F. Pacemaker Contact Sensitivity: Case Report and Review of the Literature. PACE 2002; 25:863-865

Hill PE. Complications of permanent transvenous cardiac pacing: A 14-year review of all transvenous pacemaker inserted at one community hospital. Pacing Clin Electrophysiol 1987; 10:564-570

Kearney R, Eisen HJ, Wolf JE. Nonvalvular infections of the cardiovascular system. Ann Intern Med 1994; 121:219-230

Uslan D, Sohail M, St. Sauver J, Friedman PA, Haye DL, Stoner SM, Wilson WR, Steckelberg JM, Baddour LM. Permanent pacemaker and implantable cardioverter defibrillator infection. A population-based study. Arch Intern Med 2007; 167:669-675

Aggarwal RK, Connelly DT, Ray SG, Ball J, Charles RG. Early complications of permanent pacemaker implantation: no difference between dual and single chamber systems. Br Heart J 1995; 73:571-575

Chauan A, Grace AA, Newell SA, Stone DL, Shapiro LM, Schofield PM, Petch MC. Early complications after dual-chamber versus single-chamber pacemaker implantation. Pacing Clin Electrophysiol 1994; 17:2012-2015

Sohail MR, Uslan DZ, Khan AH, et al. Management and outcome of permanent pacemaker and implantable cardioverter-defibrillator infections. J Am Coll Cardiol 2007; 49:1851-9

Eggimann P, Waldovogel FA. Pacemaker and defibrillator infections. In: Waldvogel FA, Bisno AL, eds. Infections associated with indwelling medical devices. Washington, DC: American Society for Microbiology Press, 2000:247

Bortolotti U, Tursi V, Fasoli G, Milano A, Frigato N, Casarotto D. Tricuspid valve endocarditis: repair with the use of tricuspid chordae. J Heart Valve Dis 1993; 2:56770

Klug D, Lacroix D, Savoye C, Goullard L. Systemic infection related to endocarditis on pacemaker leads: clinical presentation and management. Circulation 1997; 95:20982107

Howarth DM, Curteis PG, Gibson S. Infected cardiac pacemaker wires demonstrated by Tc99m labeled white blood cell scintigraphy. Clin Nucl Med 1998; 23:74-76

Ellenbogen KA, Kay GN, Lau CP, Wilkoff BL eds. Clinical cardiac pacing, defibrillation, and resynchronization therapy. Saunders Elsevier, Philadelphia 2007; 912-930 
Anguera I, Del-Rio A, Miro JM. Staphylococcus lugudensis infective endocarditis: description of 10 cases and analysis of native valve, prosthetic valve and pacemaker lead endocarditis-clinical profiles. Heart 2005; 91:e10

Laguno M, Miro O, Font C, de-la-Sierra A. Pacemaker-related endocarditis. Report of 7 cases and review of literature. Cardiology 1998; 90:244-8

Sharma S, Tieyjeh IM, Espinosa RE, Costello BA, Baddour LM. Pacemaker infection due to Mycobacterium fortuitum. Scand J Infect Dis 2005; 37:66-7

de Oliveira JC, Martinelli M, D'Orio Nishioka SA, Varejao T, Uipe D, Pedrosa AAA, Costa R, Danik SB. Efficacy of Antibiotic Prophylaxis Before the Implantation of Pacemakers and Cardioverter-Defibrillators. Results of a Large, Prospective, Randomized, Double-Blinded, Placebo-Controlled Trial. Circ Arrhythmia Electrophysiol 2009; 2:29-34

Tascini C, Bongiorni MG, Gemignani G, Soldati E. Management of cardiac device infection: A retrospective survey of a non surgical approach combining antibiotic therapy with transvenous removal. J Chemother 2006; 18:157-163

Ruttman E, Hangler HB, Kilo J, Hofer D. Transvenous pacemaker lead removal is safe and effective even in large vegetations: an anlysis of 53 cases of pacemaker lead endocarditis. Pacing Clin Electrophysiol 2006; 29:231-6,

Kaul P, Adluri K, Javangula K and Baig W. Successful management of multiple permanent pacemaker complications-infection, 13 year old silent lead perforation and exteriorisation following failed percutaneous extraction, superior vena cava obstruction, tricuspid valve endocariditis, pulmonary embolism and prosthetic tricuspid valve thrombosis. J of Cardithorac Surg 2009; 4:12

Chua JD, Wilkoff BL, Lee I, Juratli N, Longworth DL, Gordon SM. Diagnosis and management of infections involving implantable electrophysiologic cardiac devices. Ann Intern Med 2000; 133:604-8 


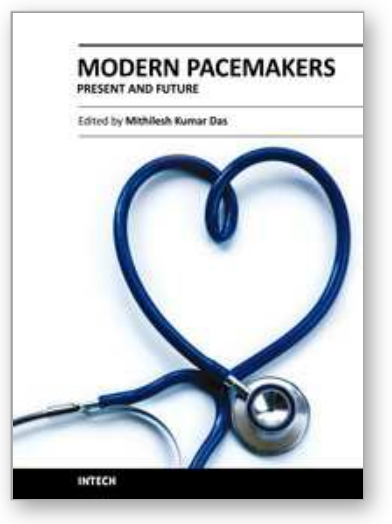

\author{
Modern Pacemakers - Present and Future \\ Edited by Prof. Mithilesh R Das
}

ISBN 978-953-307-214-2

Hard cover, 610 pages

Publisher InTech

Published online 14, February, 2011

Published in print edition February, 2011

The book focuses upon clinical as well as engineering aspects of modern cardiac pacemakers. Modern pacemaker functions, implant techniques, various complications related to implant and complications during follow-up are covered. The issue of interaction between magnetic resonance imaging and pacemakers are well discussed. Chapters are also included discussing the role of pacemakers in congenital and acquired conduction disease. Apart from pacing for bradycardia, the role of pacemakers in cardiac resynchronization therapy has been an important aspect of management of advanced heart failure. The book provides an excellent overview of implantation techniques as well as benefits and limitations of cardiac resynchronization therapy. Pacemaker follow-up with remote monitoring is getting more and more acceptance in clinical practice; therefore, chapters related to various aspects of remote monitoring are also incorporated in the book. The current aspect of cardiac pacemaker physiology and role of cardiac ion channels, as well as the present and future of biopacemakers are included to glimpse into the future management of conductions system diseases. We have also included chapters regarding gut pacemakers as well as pacemaker mechanisms of neural networks. Therefore, the book covers the entire spectrum of modern pacemaker therapy including implant techniques, device related complications, interactions, limitations, and benefits (including the role of pacing role in heart failure), as well as future prospects of cardiac pacing.

\title{
How to reference
}

In order to correctly reference this scholarly work, feel free to copy and paste the following:

Enes Elvin Gul and Mehmet Kayrak (2011). Common Pacemaker Problems: Lead and Pocket Complications, Modern Pacemakers - Present and Future, Prof. Mithilesh R Das (Ed.), ISBN: 978-953-307-214-2, InTech, Available from: http://www.intechopen.com/books/modern-pacemakers-present-and-future/commonpacemaker-problems-lead-and-pocket-complications

\section{INTECH}

open science | open minds

\section{InTech Europe}

University Campus STeP Ri

Slavka Krautzeka 83/A

51000 Rijeka, Croatia

Phone: +385 (51) 770447

Fax: +385 (51) 686166

\section{InTech China}

Unit 405, Office Block, Hotel Equatorial Shanghai

No.65, Yan An Road (West), Shanghai, 200040, China 中国上海市延安西路65号上海国际贵都大饭店办公楼 405 单元

Phone: +86-21-62489820

Fax: +86-21-62489821 
www.intechopen.com 
(C) 2011 The Author(s). Licensee IntechOpen. This chapter is distributed under the terms of the Creative Commons Attribution-NonCommercialShareAlike-3.0 License, which permits use, distribution and reproduction for non-commercial purposes, provided the original is properly cited and derivative works building on this content are distributed under the same license. 